\title{
Retinal Nerve Fibre Layer Thickness Change After CO2 Laser-Assisted Deep Sclerectomy Surgery
}

This article was published in the following Dove Press journal:

Clinical Ophthalmology

\author{
Zoltán Sohajda (iD) \\ Noémi Széll ${ }^{1}$ \\ Ágnes Revák' \\ Júlia Papp (DD' \\ Edit Tóth-Molnár (iD) \\ 'University of Debrecen, Kenézy Hospital \\ Department of Ophthalmology, \\ Debrecen, Hungary; ${ }^{2}$ University of \\ Szeged, Department of Ophthalmology, \\ Szent-Györgyi Medical and \\ Pharmaceutical Center, Szeged, Hungary
}

Purpose: The goal of our study was to investigate changes in intraocular pressure (IOP), best-corrected visual acuity (BCVA), and retinal nerve fibre layer thickness (RNFLT) after CO2 laser-assisted deep sclerectomy (CLASS).

Methods: We carried out uncomplicated CLASS surgeries and a 12-month follow-up on 22 open-angle glaucomatous (OAG) eyes of 22 patients. IOP, BCVA, and RNFLT with spectraldomain optical coherence tomography (SD OCT) were recorded before and 1, 3, 6, 12 months after surgery.

Results: Mean age of patients was 68.1 years. IOP decreased from preoperative $28.45 \pm 5.99$ $\mathrm{SD} \mathrm{mmHg}$ (mean \pm standard deviation) to $15.09 \pm 2.40 \mathrm{mmHg}(\mathrm{p}=0.00039)$ at 12 months after surgery. BCVA-change from preoperative $0.34 \pm 0.38 \mathrm{SD}$ (LogMAR) to $0.37 \pm 0.41 \mathrm{SD}$ (LogMAR) was not significant $(\mathrm{p}=0.2456)$. RNFLT-change from preoperative 60.50 $\pm 18.15 \mu \mathrm{m}$ to $59.63 \pm 17.52 \mu \mathrm{m}$ at 12 months postoperatively was not significant $(\mathrm{p}=0.056$ ). Qualified success rate of CLASS surgery was $72.7 \%$, whereas complete success rate was $64 \%$ at 1 year postoperatively.

Conclusion: Successful CLASS surgery efficiently reduced IOP. At postoperative 12 months, RNFLT and BCVA were not reduced significantly. There was no significant glaucomatous progression after surgery encountered in respect of investigated parameters.

Keywords: open-angle glaucoma, CLASS, retinal nerve fiber layer thickness, intraocular pressure, best-corrected visual acuity

\section{Introduction}

Open-angle glaucoma is a chronic, progressive optic neuropathy, which primarily affects retinal ganglion cells (RGC) and in the lack of adequate treatment eventually leads to gradual visual field- and visual acuity-loss. Insufficient IOP control and function loss in spite of maximal conservative therapy is an indication for surgical intervention. ${ }^{1}$ An adequate treatment option may be non-penetrating deep sclerectomy (NPDS), which was proven to be adequately efficient and has a higher safety profile (lower complication rate) than traditional trabeculectomy. ${ }^{2,3}$ Undesired perforation rate during the preparation of trabeculo-Descemet window might be as high as $30-50 \% .^{4}$ In order to reduce intraoperative complication rate in the course of non-penetrating deep sclerectomy, and to increase standardization and reproducibility of the surgery, $\mathrm{CO} 2$ laser was introduced in the surgical procedure. ${ }^{5}$

Publications about the human application of CO2 laser-assisted sclerectomy surgery (CLASS) see back only a few years now. ${ }^{6,7}$ Several authors report on the efficacy of the surgery. According to their results, CLASS surgery reduces IOP very efficiently, at the same time, it also has a high postoperative total success and 
qualified success rate. ${ }^{6-9}$ Geffen et al report about significant and permanent IOP reduction even after a 3-year follow-up time. ${ }^{10}$ In the latest study on the issue by Jankowska-Szmul, the efficacy of CLASS surgery and trabeculectomy was compared. She found that both surgeries reduce IOP efficiently, nevertheless, trabeculectomy results in a more pronounced IOP reduction. However, there is no significant difference in the qualified success rate of the two surgeries. At the same time, CLASS is accompanied by significantly fewer complications than trabeculectomy. ${ }^{11}$ Yu et al combined CLASS and phacoemulsification to reach efficient IOP-reduction. ${ }^{12}$ There is much less publications on the change of morphological parameters after non-penetrating glaucoma surgery, however. We only have information about the average RNFLand thus indirectly about RGC - status in the postoperative first 6 months. ${ }^{13-15}$ The goal of this prospective study was to investigate changes in IOP, best-corrected visual acuity (BCVA) and retinal nerve fibre layer thickness (RNFLT) in the course of a 12-month follow-up period after CLASS surgery, was carried out on open-angle glaucomatous eyes.

\section{Subjects and Methods}

All procedures adhered to the Declaration of Helsinki. This study was approved by the local Ethics Committee of Kenézy University Hospital. A written informed consent from all patients were obtained before the operation. Eligible patients were adults ( $>40$ years) with medically uncontrolled openangle glaucoma (primary open-angle glaucoma, pseudoexfoliative glaucoma). Medically uncontrolled was defined when no adequate glaucoma-control could be reached in spite of maximal local hypotensive therapy. Under such circumstances a glaucomatous optic neuropathy, progression of glaucomatous visual field defect, or worsening of RNFLT an open-angle (Schaffer III-IV grade) were indications for surgery. Exclusion criteria were: any intraocular surgery within 6 months, previous glaucoma surgery or laser procedure, any kind of vascular retinopathy, an optic neuropathy not attributable to glaucomatous damage and a myopic or hyperopic refractive error greater than 6D. All patients underwent a comprehensive ophthalmological examination at baseline and at 1, 3, 6 and 12 months postoperatively. These included a thorough history record, assessment of BCVA (LogMAR), anterior segment and fundus examination, Goldmann applanation tonometry, gonioscopy, pachymetry (IOL Master-700 Carl Zeiss Meditec, AG, Jena, Germany). Patients underwent visual field test (Humphrey Field Analyzer II 750, Carl Zeiss Meditec, Inc., Dublin,
USA; 24-2 SITAFAST protocol). A reliable visual field test was defined as one with less than $30 \%$ fixation loss and false positive or false negative responses. RNFLT measurements were carried out with spectral-domain optical coherence tomography (Spectralis, Heidelberg Engineering GmbH, Heidelberg, Germany; Spectralis Glaucoma Module Premium Edition, version: GMPE V6.8a). Visual field and/or RNFL-changes were taken into account when indicating surgery. ${ }^{12,14}$ Surgery was considered to be successful if the following criteria were met: postoperative IOP was between 5 and $18 \mathrm{mmHg}$ and at least 20\% IOP-reduction was achieved as compared to baseline with (qualified success rate) or without (complete success rate) additional local hypotensive therapy. ${ }^{6}$ If IOP was not in the above range in spite of administering maximal hypotensive therapy, we carried out Nd:YAG goniopuncture or needling. Patients with an intraoperative complication (macroperforation), high postoperative IOP (reoperation needed) or intraocular surgery within the 1-year interval of follow-up, were excluded from the study. Data of 22 patients' 22 eyes (out of 25 patients at baseline) over a 12-month follow-up period were analysed. We did not include a control group. To be ethical we performed the surgery in all cases when the need for surgical intervention was recognized (non-compensated cases on conservative therapy).

\section{Surgical Procedure}

All surgeries were performed by the same surgeon (Z.S.) under retrobulbar anaesthesia (1:1 mixture of bupivacaine $0.5 \%$ and lidocaine $2 \%$ ). CLASS surgeries were carried out according to the standard technique, without using antimetabolite. ${ }^{9,10}$ A peritomy with removal of the Tenon capsule and a careful cauterization was carried out in the superior quadrant. A 4x4 mm half-thickness scleral flap was dissected manually at the 12-o'clock position and a scleral pond was created with OT-135 CO2 laser device (IOPtiMate; IOPtima Ltd, Ramat Gan, Israel) using 20W laser energy. $\mathrm{CO} 2$ laser beam was then focused at the surgical limbal area, and thus, with the dissection of Schlemm's canal and the trabeculum a $3 \mathrm{~mm}$ wide trabeculo-Descemet window was created. A well functioning window was hallmarked by fluid percolation from the anterior chamber. A high viscosity viscosurgical device (Amvisc Plus, Bausch+Lomb, USA) was injected into the scleral bed, and then the sclera and conjunctiva were closed with $8 / 0$ Vicryl sutures. Patients were administered Tobramycin+Dexamethason drops 4 times daily for 1 month. 


\section{Statistical Analysis}

Snellen BCVA values were converted to the logarithm of the minimum angle of resolution (logMAR). Descriptive statistical results were presented as mean \pm standard deviation (SD). Changes from baseline of continuous variables to different endpoints were analysed with Wilcoxon test. Cumulative probability of success was illustrated using Kaplan-Meier survival curves. Multiple logistic regression analysis was performed to investigate the relationship between the different investigated variables. Spearman correlation was used to describe correlations between age, baseline IOP and change, baseline RNFLT and change, baseline BCVA and change. A $p$ value of $<0.05$ was considered significant. Analysis was performed in R software package, version 3.5.2 (R Core Team 2018).

\section{Results}

The study period was from January 2016 to June 2018. Three patients of all 25 were excluded from our study: trabeculectomy was performed in 2 cases because of intraoperative macroperforation, and another CLASS surgery was performed in 1 case in the first postoperative month. All of our patients belong to the Caucasian race. Twenty-two open-angle glaucomatous eyes (15 females, 7 males) were altogether enrolled in this study, and followed for 12 months. Mean age of patients was: 68.1 (46-87) years. In 4 cases of all 22 surgeries, an intraoperative microperforation occurred. This, however, did not disturb usual finishing of the surgery. We encountered hyphaema as a complication in the early postoperative period (1 month), which resolved spontaneously. Choroidal detachment occurred postoperatively in one case (1 month), that resolved without any additional surgical correction. We needed to carry out needling in 4 cases and Nd:YAG goniopuncture in 4 cases in the first 3 postoperative months.

We analysed data at postoperative 1, 3, 6 and 12 months. We measured IOP, recorded BCVA, and evaluated RNFLT on average and in each sector one by one (superior nasal: $\mathrm{SN}$, nasal: $\mathrm{N}$, inferior nasal: $\mathrm{IN}$, inferior temporal: IT, temporal: T, superior temporal: ST). Patient's clinical characteristics are summarized in Table 1.

Mean preoperative IOP was $28.45 \pm 5.99 \mathrm{SD} \mathrm{mmHg}$, which decreased to $16.0 \pm 1.77 \mathrm{SD} \mathrm{mmHg}$ at $1 \mathrm{st}$ $(\mathrm{p}=0.00039)$, to $16.72 \pm 1.90 \mathrm{SD} \operatorname{Hgmm}$ at $3 \mathrm{rd}(\mathrm{p}=$ $0.00058)$, to $15.54 \pm 2.17 \mathrm{SD}$ Hgmm at 6 th $(\mathrm{p}=0.00039)$ and to $15.09 \pm 2.40 \mathrm{SD}$ Hgmm at 12 th $(\mathrm{p}=0.00039)$ postoperative month. Changes compared to baseline values were all significant. Mean preoperative $0.34 \pm 0.38$ SD BCVA
Table I Patient's Clinical Characteristics Before the Surgery

\begin{tabular}{|l|l|l|}
\hline & Mean \pm SD & Range \\
\hline Age (year) & $68.1 \pm 15.6$ & $46-87$ \\
Medication & $2.80 \pm 0.75$ & $1-4$ \\
CCT $(\mu \mathrm{m})$ & $542.25 \pm 32.53$ & $485-590$ \\
IOP $(\mathrm{mmHg})$ & $28.45 \pm 5.99$ & $18-42$ \\
MD $(\mathrm{dB})$ & $-10.8 \pm 8.3$ & -24.7 to 0.4 \\
BCVA (logMar) & $0.34 \pm 0.38$ & $0-1.0$ \\
RNFLT $(\mu \mathrm{m})$ & $60.50 \pm 18.15$ & $40-96$ \\
\hline
\end{tabular}

Abbreviations: $C C T$, central corneal thickness; IOP, intraocular pressure; MD, mean deviation; BCVA, best-corrected visual acuity; RNFLT, retinal nerve fiber layer thickness.

changed to $0.36 \pm 0.39 \mathrm{SD}(\mathrm{p}=0.026), 0.37 \pm 0.40 \mathrm{SD}$ $(\mathrm{p}=0.055), 0.37 \pm 0.41 \mathrm{SD}(\mathrm{p}=0.20)$ and $0.37 \pm 0.41 \mathrm{SD}$ $(\mathrm{p}=0.24)$, respectively. Improvements at 1 month were significant, whereas changes at 3,6 and 12 month were not significant compared to baseline values.

Preoperatively measured RNFLT was: $60.50 \pm 18.15$ SD $\mu \mathrm{m}$ and then $62.27 \pm 18.20 \mathrm{SD} \mu \mathrm{m}(\mathrm{p}=0.011), 59.72 \pm 17.42$ $\mathrm{SD} \mu \mathrm{m}(\mathrm{p}=0.26), 59.54 \pm 17.19 \mathrm{SD} \mu \mathrm{m}(\mathrm{p}=0.074)$ and 59.63 $\pm 17.52 \mathrm{SD} \mu \mathrm{m}(\mathrm{p}=0.0564)$, respectively, at each follow-up time. At 1 month, RNFLT compared to baseline was statistically significantly thicker, however, later on differences were not significant (Table 2). Changes of BCVA, RNFLT over time are shown in Figures 1 and 2. We also analysed RNFLT in different sectors postoperatively. At 1 month, RNFLT was statistically significantly thicker in many sectors (SN,N,IN, IT, T) as compared to baseline: SN from $83.55 \pm 35.26 \mathrm{SD} \mu \mathrm{m}$ to $85.32 \pm 33.80 \mathrm{SD} \mu \mathrm{m}(\mathrm{p}=0.036)$, $\mathrm{N}$ from $54.95 \pm 19.91 \mathrm{SD} \mu \mathrm{m}$ to $57.77 \pm 18.39 \mathrm{SD} \mu \mathrm{m}(\mathrm{p}=$ 0.017), IN from $73.50 \pm 24.8 \mathrm{SD} \mu \mathrm{m}$ to $74.91 \pm 23.12 \mathrm{SD} \mu \mathrm{m}$ $(p=0.032$ ), IT from $75.14 \pm 37.17$ SD $\mu \mathrm{m}$ to $77.86 \pm 34.52 \mathrm{SD}$ $\mu \mathrm{m}(\mathrm{p}=0.025), \mathrm{T}$ from $48.64 \pm 12.07 \mathrm{SD} \mu \mathrm{m}$ to $54.09 \pm 13.36$ $\mathrm{SD} \mu \mathrm{m}(\mathrm{p}=0.0007)$. RNFLT - change in ST sector was not significant at 1 month: from $80.73 \pm 35.62 \mu \mathrm{m}$ to 82.91 \pm 32.89 , SD $\mu \mathrm{m}(\mathrm{p}=0.087)$. Apart from these, there were no significant changes in RNFLT in any sectors within the 12 months. Data are presented in Figure 3. Figure 4 shows a 62 years old male patient's RNFLT in different sectors pre and 12 months postoperatively (Figure 4A and B). We intended to identify correlations (Pearson correlation) between different investigated parameters: age, baseline IOP and change, baseline RNFLT and change, baseline BCVA and change. We found correlation merely between BCVA-change and IOP-change $(\mathrm{r} 2=0.234, \mathrm{p}=0.022)$, and between the baseline BCVA and baseline IOP $(\mathrm{r} 2=0.281$, $\mathrm{p}=0.0112$ ). We analysed the efficacy of CLASS surgery in 
Table 2 The Everage Data of Investigated Parameters Postoperatively

\begin{tabular}{|l|l|l|l|l|l|l|}
\hline & IOP \pm SD & P value & BCVA \pm SD & P value & RNFLT \pm SD & P value \\
\hline Preop. & $28.45 \pm 5.99$ & - & $0.34 \pm 0.38$ & - & $60.50 \pm 18.15$ & - \\
I mo. & $16.0 \pm 1.77$ & $0.00039^{*}$ & $0.36 \pm 0.39$ & $0.026 *$ & $62.27 \pm 18.20$ & $0.011^{*}$ \\
3 mo. & $16.72 \pm 1.90$ & $0.00058^{*}$ & $0.37 \pm 0.40$ & 0.055 & $59.72 \pm 17.42$ & 0.261 \\
6 mo. & $15.54 \pm 2.17$ & $0.00039^{*}$ & $0.37 \pm 0.41$ & 0.206 & $59.54 \pm 17.19$ & 0.074 \\
12 mo. & $15.09 \pm 2.44$ & $0.00039^{*}$ & $0.37 \pm 0.41$ & 0.245 & $59.63 \pm 17.52$ & 0.056 \\
\hline
\end{tabular}

Notes: $\mathrm{p}$ : level of significance. $\mathrm{P}<0.05$ is marked $*$.

Abbreviations: IOP (Hgmm), intraocular pressure, BCVA (LogMAR), best-corrected visual acuity; RNFLT ( $\mu$ m), peripapillary nerve fibre layer thickness; SD, standard deviation.

respect of qualified success rate and complete success rate. According to our results, qualified success rate was $90.9 \%$ at 1 month, $86.3 \%$ at 3 months, $77 \%$ at 6 months and $72.7 \%$ at 12 months postoperatively. Complete success rate was $86.3 \%, 77 \%, 72.7 \%, 64 \%$, respectively. Figure 5 shows Kaplan-Meier plots of cumulative probability of complete success and qualified success.

\section{Discussion}

The efficacy of CLASS surgery in lowering IOP is confirmed by numerous studies. ${ }^{6,7,9-12}$ NPDS is the surgical basis for CLASS surgery, and it was proved by Gesser to efficiently stabilize visual field over an 8 -year period. ${ }^{3}$ Greifner compared the efficacy of NPDS and CLASS in terms of IOP-reduction, and reported total success rate and qualified success rate of CLASS be better than that of NPDS. ${ }^{16}$ IOP reduction is adequate 3 years postoperatively after CLASS. ${ }^{10}$ Our results of $72.7 \%$ qualified success rate and $64 \%$ complete success rate at the 12 months end point of follow-up are in accordance with the latest reports on this issue, which report on $74-91 \%$ qualified success rate and $35-73 \%$ complete success rate. ${ }^{10,12,16,17}$

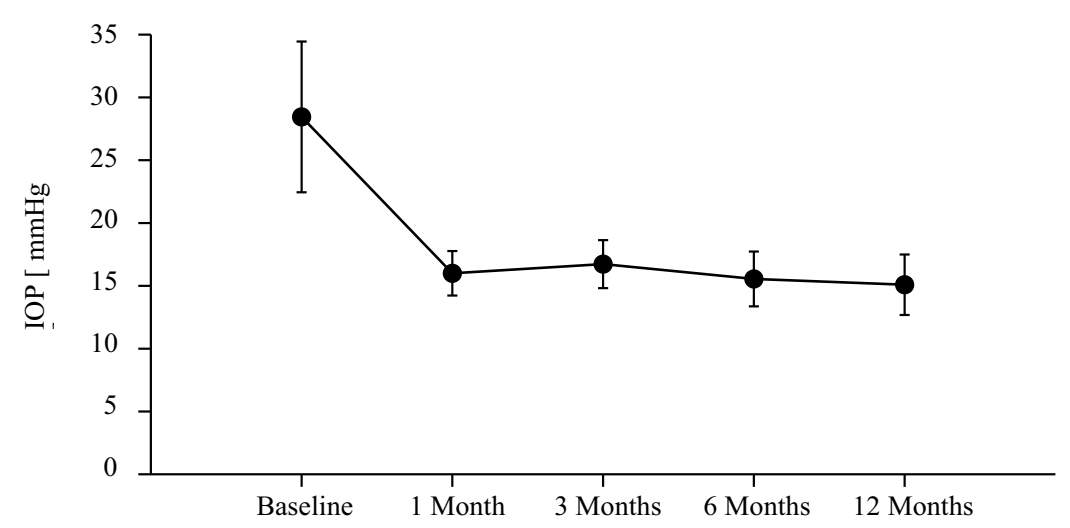

Figure I Cumulative IOP \pm SD measurements from the preoperative stage up to 12 months postoperatively.

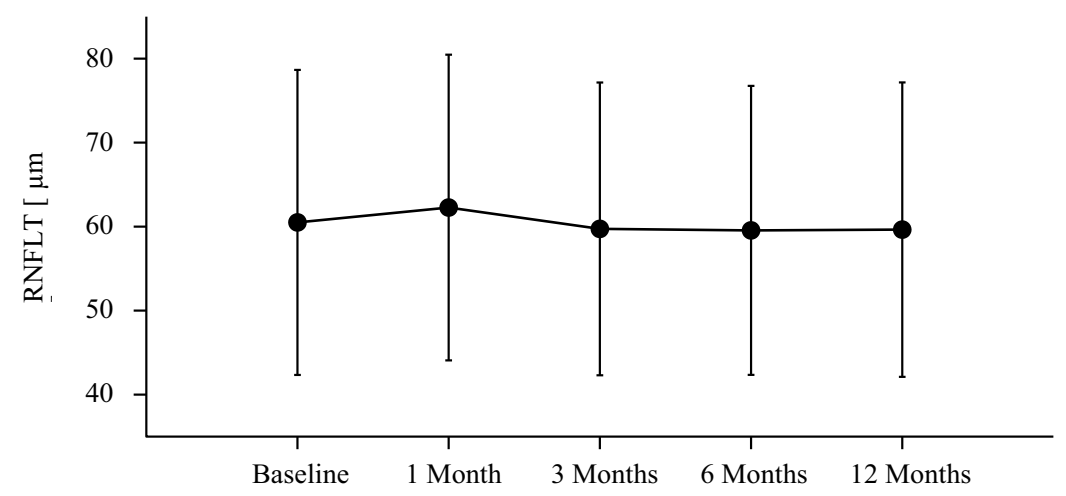

Figure 2 Cumulative RNFLT \pm SD measurements from the preoperative stage up to 12 months postoperatively. 


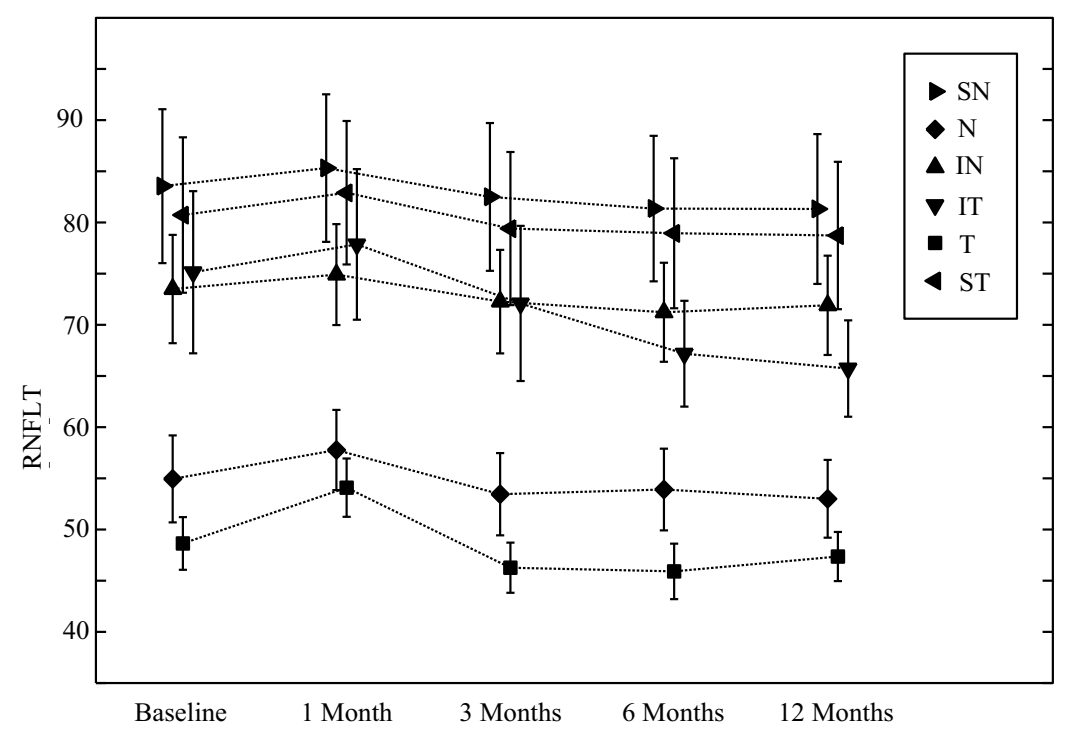

Figure 3 Line graphs showing comparison of the six sectors of RNFL thickness at each control visit with respect to the baseline values.

There are studies designed to examine functional parameters related to CLASS surgery; however, there is no research article published on retinal morphological changes after CLASS up to date. Optical coherence tomography (OCT) provides a good possibility to demonstrate these changes. It is a non-invasive, real-time and objective method to scan retinal parameters quantitatively. ${ }^{14}$ IOP-changes correlate well with RNFLT-changes. The most affected layer of RNFL in respect of glaucomatous damage is located in the level of lamina cribrosa. Structure of this layer, however, is not uniform: it is thicker nasally than in other sectors. ${ }^{18}$ There are studies conducted to evaluate the correlation between different methods of glaucoma surgery and RNFLT. These studies, however, are diverse, and investigate RNFLT-change in terms of disparate surgical techniques. Part of these articles report on an RNFLT-increase in the first 3-4 months postoperatively after trabeculectomy. In these studies, it is suggested that the thickness of prelaminar tissue is influenced by IOP. ${ }^{13,15,19-21}$ According to research articles about NPDS, postoperative IOP-reduction is not associated with significant RNFLT-change at 6 months postoperatively. ${ }^{13,14}$ Studies reporting on the condition of lamina cribrosa and peripapillary RNFLT after trabeculectomy or NPDS draw the same conclusion: changes in the morphology of the optic nerve head attributable to postoperative IOP-changes (anterior displacement of the lamina cribrosa, reduced cup volume and increased rim area) are not necessarily accompanied by an increase in the RNFLT. ${ }^{4,17,21-24}$ Reduction of cup volume can be detected if significant IOP lowering (according to some authors at least $30 \%$ or according to others even less) is realized. ${ }^{13,22,25}$ Changes in RNFLT in correlation with IOP changes were likewise measured. According to some authors, there is an $0.5 \mu \mathrm{m}$ increase in RNFLT in case of a $1 \mathrm{mmHg}$ IOP-reduction, according to others, a $1.3 \mathrm{mmHg}$ IOP-lowering is needed to achieve this goal. ${ }^{14,19,26}$ There is not a tight correlation between the morphological changes of the optic nerve head and RNFLT. Explanation for this observation might be that IOP-reduction does not result in an increase of the number of axons, rather, it causes relaxation of the axons and reduces tissue strain, and this would lead to a morphological change of the optic nerve head. However, this restoration is biomechanical or physiological, rather than anatomical. ${ }^{14}$ Krzyżanowska-Berkowska et al studied the differences between trabeculectomy and NPDS. They found that the thickening of the prelaminary tissue area (axons, capillaries, extracellular materials) after trabeculectomy was more explicit, than in the NPDS group. ${ }^{13}$ Hypotony may result in an increase in the overall retinal thickness, and this may account for the RNFLT-increase encountered after trabeculectomy and more infrequently after NPDS. This fact may lead to false interpretation of RNFLT-increase after trabeculectomy. ${ }^{15,19,20}$ Authors evaluating RNFLT-changes after NPDS surgery analyse patients' records with dissimilar pre- and postoperative RNFLT: Rebolleda measured $66.6 \mu \mathrm{m}$ mean RNFLT in her patients group, whereas KrzyżanowskaBerkowska's patients had $61.6 \mu \mathrm{m}$ average RNFLT at baseline. Among our subjects the mean RNFLT was $60.50 \mu \mathrm{m}$ at baseline and $59.63 \mu \mathrm{m}$ at 12 -month end point of the followup. We compared our patients' results of RNFLT-changes to those of Rebolleda, who carried out NPDS surgery. It is 

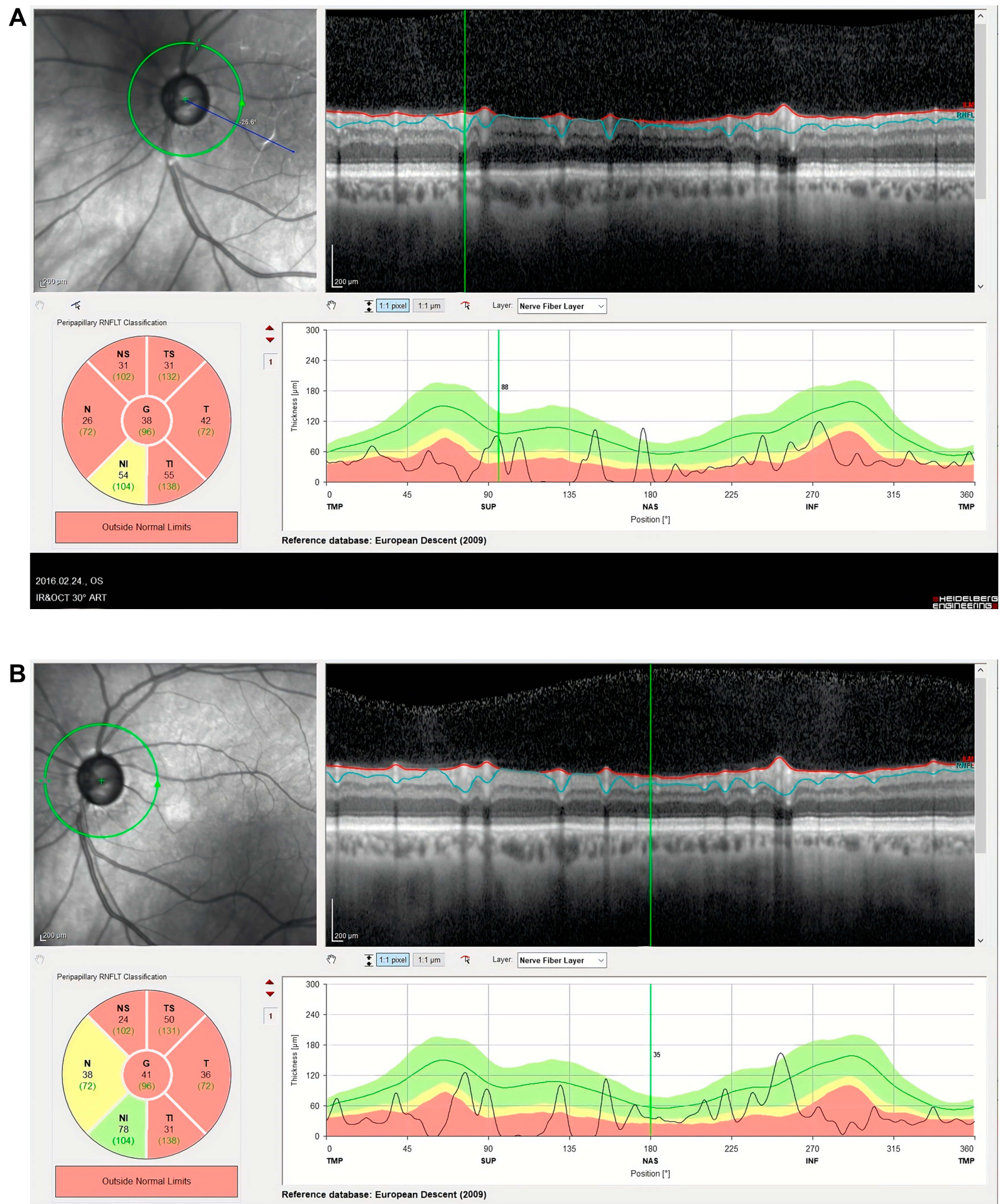

\subsubsection{3., OS}

IR\&OCT $30^{\circ}$ ART

Figure 4 (A) Preoperative OCT image of a 62-year-old male patient displaying significantly reduced RNFLT in all except for the inferonasal sector. (B) RNFLT image of the same patient I year postoperatively: significantly reduced RNFLT in all but the nasal and inferonasal sectors, mean RNFLT is unaltered. 


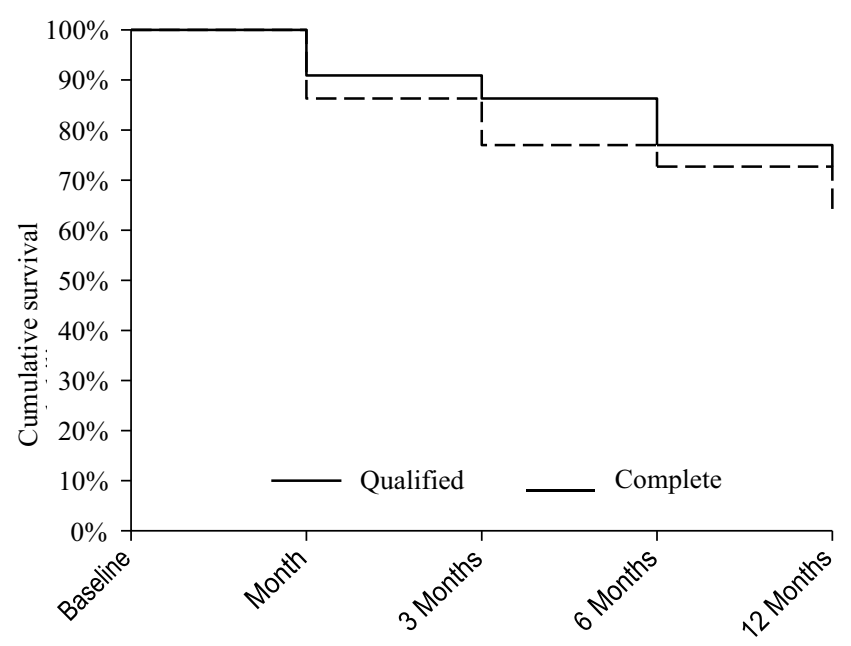

Figure 5 Kaplan-Meier plots of the cumulative probability of complete success (dashed line) and qualified success (continuous line) for CO2 laser-assisted sclerectomy surgery (CLASS).

known that it is problematic to compare progression rates expressed in terms of RNFLT-changes measured with different OCT systems. ${ }^{13,14,28}$ Lower mean baseline RNFLT score of our candidates indicates that patients in Hungary are assigned for glaucoma surgery at a more advanced stage of glaucomatous damage. ${ }^{27}$ Rebolleda found RNFLT-change to be higher in patients with a preoperative RNFLT smaller than $62 \mu \mathrm{m}$ than in patients with a preoperative RNFLT higher than $62 \mu \mathrm{m} .^{14}$

When evaluating RNFLT-changes measured with spectral-domain OCT, we must take into account the fact that the average RNFLT-reduction per year might be as high as $0.33 \mu \mathrm{m}$ in healthy eyes whereas $0.69 \mu \mathrm{m}$ in glaucomatous eyes being on maximal medical therapy. ${ }^{28}$ Mean RNFLTchange in our subjects was $-0.87 \mu \mathrm{m}$ at 12 months. This is comparable to Holló's previous data. Our data suggest that CLASS as a non-penetrating procedure effectively reduces RNFLT decrease on an overall 12-month follow-up. Several other authors investigated RNFLT-change after NPDS procedure and they found no significant changes as compared to baseline at 6 months postoperatively. ${ }^{13,14}$

Krzyżanowska-Berkowska et al investigated RNFLTchanges per sectors following NPDS surgery. At postoperative 6 months, they observed a significant RNFLT-reduction in TS and TI sectors but found no significant changes in the rest of the 4 sectors or on average either. ${ }^{13}$ We encountered a significant increase in mean RNFLT in almost all sectors (except ST) and on average as well at 1 month after surgery. Similar results were reported by many authors after trabeculectomy and NPDS surgery in the early postoperative period.
The mechanism that could explain the thickening of RNFLT after corresponding IOP reduction is unclear. It is possible, however, that some axons are still able to function during periods of elevated IOPs and can recover some physiologic function after IOP is lowered. ${ }^{14}$ Nevertheless, at 6 and 12 months postoperatively there was no significant thinning in the mean RNFLT either per sectors or on average as compared to baseline. ${ }^{13,14,19,21}$ RNFLT-increase in the early postoperative period might be attributed to the major IOPreduction encountered during this period, although we could find no correlation between these two parameters.

We could only find correlation between BCVA-changes and IOP-reduction: a greater IOP-reduction was accompanied by a greater improvement in BCVA. Another correlation was found between baseline IOP and baseline BCVA. The higher the baseline IOP was, the lower the baseline BCVA. According to Jankowska-Szmul and Cutulo, BCVA does not change significantly after CLASS surgery. ${ }^{11,29}$ In our study, we could confirm these findings. This might be attributed to two different factors. The first is that there was only a mild progression of cataract. The second is that there was no significant change in RNFLT after NPDS surgery, albeit the latter is one of the most important criterion of maintaining a good visual function. ${ }^{1,13,14}$ An interesting point in our study is that a significant temporary BCVAimprovement at 1 month postoperatively was encountered. There might be multiple reasons in the background of this explanations for this finding. One is the thickening of RNFLT, which can be attributed to the decompression of axons after adequate IOP reduction. ${ }^{14}$ Next is the high percentage of complete success rate observed in the early postoperative period. The lower amount of eye drops used in this period might account for an increased tear film stability and thus the visual acuity improvement. ${ }^{30}$

To conclude, IOP control by successful CLASS may result in stability of RNFL thickness after CLASS surgery in the investigated period, while a significant IOPreduction was achieved at 12 months postoperatively. Limitation of our study is the relatively small number of patients enrolled. However, taking into account that to our knowledge, there is no other study apart from ours up to date dealing with this issue, this present research might be a good baseline for further investigations.

\section{Informed Consent}

Informed consent was obtained from all participants included in the study. 


\section{Funding}

No funding was received for this research.

\section{Disclosure}

None of the authors declare any conflict of interest relevant to the article.

\section{References}

1. EGS European glaucoma society terminology and guidelines for glaucoma, 4th edition - chapter 3: treatment principles and options. Supported by the EGS Foundation. Br J Ophthalmol. 2017;101 (6):130-195. doi:10.1136/bjophthalmol-2016-EGSguideline.003

2. Eldaly MA, Bunce C, Elsheikha OZ, Wormald R. Non-penetrating filtration surgery versus trabeculectomy for open-angle glaucoma. Cochrane Database Syst Rev. 2014;15(2):1-40.

3. Gesser C, Wiermann A, Keserü M, Richard G, Klemm M. Long-term follow-up after deep sclerectomy. Klin Monbl Augenheilkd. 2014;231 (5):535-539. doi:10.1055/s-0033-1360380

4. Khaw PT, Siriwardena D. "New" surgical treatments for glaucoma. Br J Ophthalmol. 1999;83(1):1-2. doi:10.1136/bjo.83.1.1

5. Assia EI, Rotenstreich Y, Barequet IS, Apple DJ, Rosner M, Belkin M. Experimental studies on nonpenetrating filtration surgery using the $\mathrm{CO}_{2}$ laser. Graefes Arch Clin Exp Ophthalmol. 2007;245 (6):847-854. doi:10.1007/s00417-006-0413-4

6. Geffen N, Ton Y, Degani J, Assia EI. $\mathrm{CO}_{2}$ Laser assisted sclerectomy surgery, part II: multicenter clinical preliminary study. J Glaucoma. 2012;21(3):193-198.

7. Geffen N, Ton $\mathrm{Y}$, Munoz G, et al. $\mathrm{CO}_{2}$ laser-assisted sclerectomy surgery for open- angle glaucoma. Eur Ophthal Rev. 2012;6:12-16. doi:10.17925/EOR.2012.06.01.12

8. Sogano S, Tomita G, Kitazawa Y. Changes in retinal nerve fiber layer thickness after reduction of intraocular pressure in chronic open-angle glaucoma. Ophthalmology. 1993;100(8):1253-1258. doi:10.1016/S0161-6420(93)31497-1

9. Sohajda Z, Káldi I, Kiss M, Facskó A. Experiences with $\mathrm{CO} 2$ laser-assisted sclerectomy surgery. Orv Hetil. 2017;158 (18):701-705. doi:10.1556/650.2017.30754

10. Geffen N, Mimouni M, Sherwood M, Assia EI. Mid-term clinical results of $\mathrm{CO}_{2}$ laser assisted sclerectomy surgery (CLASS) for open angle glaucoma treatment. J Glaucoma. 2016;25(12):946-951. doi:10.1097/IJG.0000000000000437

11. Jankowska-Szmul J, Dobrowolski D, Wylegala E. CO2 laser-assisted sclerectomy surgery compared with trabeculectomy in primary open-angle glaucoma and exfoliative glaucoma. A 1-year follow-up. Acta Ophthalmol. 2018;96(5):582-591. doi:10.1111/aos.13718

12. Yu X, Chen C, Sun M, et al. CO2 laser-assisted deep sclerectomy combined with phacoemulsification in patients with primary open-angle glaucoma and cataract. J Glaucoma. 2018;27 (10):906-909. doi:10.1097/IJG.0000000000001056

13. Krzyżanowska-Berkowska P, Melińska A, Helemejko I, Robert Iskander D. Evaluating displacement of lamina cribrosa following glaucoma surgery. Graefes Arch Clin Exp Ophthalmol. 2018;256 (4):791-800. doi:10.1007/s00417-018-3920-1

14. Rebolleda G, Muñoz-Negrete M, Noval S. Evaluation of changes in peripapillary nerve fiber layer thickness after deep sclerectomy with optical coherence tomography. Ophthalmology. 2007;114(3):488-493. doi:10.1016/j.ophtha.2006.06.051
15. Sarkar KC, Das P, Pal R, Shaw C. Optical coherence tomographic assessment of retinal nerve fiber layer thickness changes before and after glaucoma filtration surgery. Oman J Ophthalmol. 2014;7(1):3-8. doi:10.4103/0974-620X.127910

16. Greifner G, Roy S, Mermoud A. Results of $\mathrm{CO}_{2}$ laser-assisted deep sclerectomy as compared with conventional deep sclerectomy. $J$ Glaucoma. 2016;25(7):630-638. doi:10.1097/IJG.0000000000 000187

17. Skaat A, Goldenfeld M, Cotlear D, Melamed S. $\mathrm{CO}_{2}$ laser-assisted deep sclerectomy in glaucoma patients. J Glaucoma. 2014;23 (3):179-184. doi:10.1097/IJG.0b013e3182707406

18. Radius RL. Regional specificity in anatomy at the lamina cribrosa. Arch Ophthalmol. 1981;99(3):478-480. doi:10.1001/archopht.1981. 03930010480020

19. Aydin A, Wollstein G, Price LL, Fujimoto JG, Schuman JS. Optical coherence tomography assessment of retinal nerve fiber layer thickness changes after glaucoma surgery. Ophthalmology. 2003;110 (8):1506-1511. doi:10.1016/S0161-6420(03)00493-7

20. Raghu N, Pandav SS, Kaushik S, Ichhpujani P, Gupta A. Effect of trabeculectomy on RNFL thickness and optic disc parameters using optical coherence tomography. Eye. 2012;26(8):1131-1137. doi:10. 1038/eye.2012.115

21. Lommatzsch C, Rothaus K, Koch JM, Heinz C, Grisanti S. Retinal perfusion 6 months after trabeculectomy as measured by optical coherence tomography. Int Ophthalmol. 2019;39(11):2583-2594. doi:10.1007/s10792-019-01107-7

22. Lee EJ, Kim TW, Weinreb RN, Kim H. Reversal of lamina cribrosa displacement after intraocular pressure reduction in open-angle glaucoma. Ophthalmology. 2013;120(3):553-559. doi:10.1016/j. ophtha.2012.08.047

23. Irak I, Zangwill L, Garden V, Shakiba S, Weinreb RN. Am $J$ Ophthalmol. 1996;122(5):690-695. doi:10.1016/S0002-9394(14) 70488-X

24. Lesk MR, Spaeth GL, Azuara-Blanco A, et al. Reversal of optic disc cupping after glaucoma surgery analyzed with a scanning laser tomography. Ophthalmology. 1999;106(5):1013-1018. doi:10.1016/ S0161-6420(99)00526-6

25. Parrish RK, Feuer WJ, Schiffman JC, Lichter PR, Musch DC, CIGTS Optic Disc Study Group. Five-year follow-up optic disc findings of the Collaborative Initial Glaucoma Treatment Study. $\mathrm{Am}$ J Ophthalmol. 2009;147(4):717-724. doi:10.1016/j.ajo.2008.10.007

26. Shaarawy T, Mansouri K, Schnyder C, Ravinet E, Achache F, Mermoud A. Long-term results of deep sclerectomy with collagen implant. J Cataract Refract Surg. 2004;30(6):1225-1231. doi:10. 1016/j.jcrs.2003.10.035

27. Holló G, Schmidl D, Hommer A. Referral for first glaucoma surgery in Europe, the ReF-GS study. Eur $J$ Ophthalmol. 2019;29 (4):406-416. doi:10.1177/1120672118791937

28. Holló G, Zhou Q. Evaluation of retinal nerve fiber layer thickness and ganglion cell complex progression rates in healthy, ocular hypertensive, and glaucoma eyes with the avanti RTVue-XR optical coherence tomography based on 5-year follow-up. J Glaucoma. 2016;25 (10):905-909. doi:10.1097/IJG.0000000000000410

29. Cutolo CA, Bagnis A, Scotto R, Bonzano C, Traverso CE. Prospective evaluation of $\mathrm{CO} 2$ laser-assisted sclerectomy surgery (CLASS) with Mitomycin C. Graefes Arch Clin Exp Ophthalmol. 2018;256(1):181-186. doi:10.1007/s00417-017-3844-1

30. Kaido M. Functional visual acuity. Invest Ophthalmol Vis Sci. 2018;59(14):DES29-DES35. doi:10.1167/iovs.17-23721 


\section{Publish your work in this journal}

Clinical Ophthalmology is an international, peer-reviewed journal covering all subspecialties within ophthalmology. Key topics include: Optometry; Visual science; Pharmacology and drug therapy in eye diseases; Basic Sciences; Primary and Secondary eye care; Patient Safety and Quality of Care Improvements. This journal is indexed on PubMed

Submit your manuscript here: https://www.dovepress.com/clinical-ophthalmology-journal
Central and CAS, and is the official journal of The Society of Clinical Ophthalmology (SCO). The manuscript management system is completely online and includes a very quick and fair peer-review system, which is all easy to use. Visit http://www.dovepress.com/ testimonials.php to read real quotes from published authors. 